DOI https://doi.org/10.36059/978-966-397-150-6/46-65

\title{
PSYCHOLOGICAL READINESS OF BORDER GUARDS TO TAKE RISKS IN THEIR PROFESSIONAL ACTIVITIES
}

\section{Mykhailo Tomchuk}

\section{INTRODUCTION}

Modern professional activity of military personnel of the State Border Guard Service of Ukraine is risky because it is accompanied by a variety of situations that threaten to preserve their health, and sometimes even life. Performing service duties at the border often requires the person to take operational decisions, to resolve problematic situations quickly and demands risky behavior. The success of a border guard-officer's professional activities in special, extreme conditions depends on his/her psychological readiness for risk. Such readiness should be formed during the cadets' training at the National Academy of the State Border Guard Service of Ukraine (NASBGSU). The indicator of the level of its formation is the service results, the duration of young officers' adaptation to professional activities at the state border, their ability to take thoughtful, optimal, quick decisions in risky conditions. As practice shows, in the conditions of real professional activities at the border, in dangerous and extreme situations the graduates of the Academy quite often manifest destructive personal states: instability, impulsiveness, anxiety, aggressiveness and others that should be overcome quickly and effectively.

The analysis and generalization of the results of scientific developments on the problem of person's risk leads to the conclusion about the insufficient level of its solution at the psychological level, a certain fragmentation of the solution, the lack of studies of special features of risky behavior manifestation in the professional activities of border guards, the prediction of its expressiveness and consequences depending on their age, service term, etc.

Due to the abovementioned facts, it is relevant to study this problem at both theoretical and experimental levels. 


\section{Theoretical and psychological analysis of a person's risk as a phenomenon}

The study of risk as a person's psychological phenomenon necessarily involves understanding its objective and subjective nature. Today in psychology there is no conventional and agreed approach to understanding the concept of "risk", its conceptual and operational content.

A considerable number of researchers believes that the environment of risk manifestation is some objectively existing uncertainty, which creates a situation of unpredictability of events, spontaneity of phenomena, limited resources in planning and implementing decisions. Yu. Kozeletskyi ${ }^{1,2}$ believes that the most typical sign of risky behavior is some uncertainty of the results that will be obtained by the person who shows such behavior. In psychological researches, there are several areas of risk study and its interpretation: risk as a degree of failure; risk as a situation of choosing options for actions; risk as an assessment of a subject's situational activity and the uncertainty of its outcome (Kozeletskyi, 1979; Ilyin, 2012).

The main characteristics of risk as a manifestation of human freedom in relation to the objective situation and their own internal subjective qualities. The author defines risk as activity:

1. Risk is an activity performed by a subject despite the perceived risk of a failure.

2. Risk is an activity in which a person still counts on success in an ambiguous situation. Therefore, it must be subjectively armed with the hope of achieving the goal. Otherwise, its activities may not be considered risky but adventurous.

3. Risk is an activity with the conscious (or even, despite the conscious) possibility of a permissible error in the activity itself after achieving its goal.

4. Risk is an image of actions in an unclear, uncertain situation, when it is difficult to choose a very definite and unambiguous variant of behavior, but it is impossible to delay the action choosing for one reason or another (objective or subjective). That is, risk is an action in

\footnotetext{
${ }^{1}$ Kozeletskyi, Yu., (1979). Psychological theory of solutions. Moscow: Progress.

${ }^{2}$ Ilyin, Ye., (2012). Psychology of risk. SPb.: St. Petersburg.
} 
a situation where one cannot act. Therefore, a person is forced to "free" himself from the characteristics of an objective situation and his own subjective readiness for action.

5. Risk is a situational characteristic of an activity that a person performs in the hope of success in the context of lack of preparedness and confidence in achieving the goal.

The optimal strategy for behavior in an uncertain situation is free choice. Therefore, the subject tries to create and maintain such an opportunity. So, it will be fair to see an essential characteristic of human activity in the risk.

The person's dominant characteristic in the context of risk is the "search for sensation". There are four elements in this personal aspect: the search for thrills and adventures; search for experience; excessive activity; tendency to be bored. There is a link between the search for sensation and certain types of risky behavior, such as risky financial decision making, high gambling rates, participation in dangerous sports, socially dangerous behavior and reckless driving. One explanation for the connection that exists between "sensation seeking" and risky behavior is the tendency to reduce risk.

Risk is defined as the activity (actions) of an individual aimed at obtaining the desired result by avoiding danger, making a choice with the hope of success in a situation with a possible inauspicious result, receiving rewards, affirmation in the eyes of others or self-affirmation, trying to expand the limits of his own capabilities, achieving the goals or the realization of the desire to get a thrill. The result of such activity is always uncertain and may be unfavorable, i.e. accompanied by loss, damage, trauma, etc.

Ye.P. Ilyin ${ }^{3}$ identifies risk with strong-willed qualities: courage, daring, determination, etc. (Iliin, 2012).

K. K. Platonov believes that risk is an appeal to an activity in the absence of confidence in achieving its goal. V.A. Petrovskyi ${ }^{4}$ assumes that risk has a pragmatic tendency related to the calculation of the chances for success (for the sake of approval, money, career, etc.) (Petrovskyi, 1974).

\footnotetext{
${ }^{3}$ Ilyin, Ye., (2012). Psychology of risk. SPb.: St. Petersburg.

4 Petrovskyii, V., (1974). Human behavior in situations of danger (to the psychology of risk). New researches in psychology, (1), p. 23-24. 
Other scientists ${ }^{5}$ define risk as a measure of expected well-being in failure; as a deed or action that threaten the entity to lose something; as a decision making, i.e. a choice between options for actions (which are safer, more attractive) (Petrovskyi, Yaroshevskyi, 1990, p. 308-309).

In the theory of Aisenko's ${ }^{6}$ personality (H. Aisenk, M. Aisenk, 2001), risk is the identical desire for thrills or impulsivity and is a constitutional property of the individual. In our opinion, risk should be considered as a complex phenomenon related to the subject's behavior in a dangerous situation when the outcome of the action is determined by the decision. If the decision choice depends entirely on the subject, a dangerous situation becomes a risky situation.

According to V. Petrovskyi ${ }^{7}$, there is even such a special form of risk as "risk for the sake of risk", which is characterized by the tendency of the subject to approach danger in situations without any external necessity. Such behavior can be considered even as a type of personal disorder and characterize a person's ability to assess his own capabilities adequately (Petrovskyi, 1974, p. 77).

It can be concluded that the risk involves the danger presence that functions as certain uncertainty, the need to choose an alternative way out of it, the ability to assess the probability of its implementation. Border guards often have to take risks: both to take decisions independently in dangerous situations of professional activity and to get into them due to different circumstances - a necessary risk. After all, they have to act very often in the conditions of uncertainty, lack of complete and reliable information, false or excessive information, in situations of high dynamics of events, suddenness, unexpectedness of their occurrence, etc.

On the one hand danger is a component of risk and may be perceived by a serviceman to a different extent, on the other hand, it is an objective factor and the result of the influence of external negative factors (for example, border violations, natural disasters, conflicts

5 Petrovskyi, A., Yaroshevskyi, M. (Eds.). (1990). Short Psychological Dictionary. M.: Politizdat.

${ }^{6}$ Aisenk, H., Aisenk, M. (2001). Research of the human psyche. M.: EKSMO-Press.

7 Petrovskyi, V., (1974). Human behavior in situations of danger (to the psychology of risk). New researches in psychology, (1), p. 23-24. 
among citizens of the border area, etc.). Danger is not equivalent to the concept of risk. It exists objectively, by itself and at some point it is not associated with risk, it is a category of reality that exists outside and beyond the consciousness of a person. Risk as a phenomenon of psychology, is always subjective, because it acts as a fact of human consciousness, his evaluation of action, rational decision making taking into account the choice of one of several possible alternatives. To some extent the risk reduces the situation uncertainty, but the factors that gave rise to it still remain. The uncertainty sources may be: certain limitations in activity, lack of resources in decision making and their implementation; relativity of the person's process of the surrounding reality cognition; impossibility of unambiguous knowledge of the object; certain limitations of conscious activity, differences in psychological attitudes, ideals, intentions, assessments, stereotypes of human behavior, etc.

Risky behavior is often manifested in extreme situations, when several unfavorable for a person conditions and harmful factors coincide, and which, as a rule, require the protection of his life and health, his physical and spiritual forces. An extreme situation is considered as a set of external conditions of human activities. Its characteristics are environmental conditions of threats and dangers.

Risk is also a driving force, a contradiction for the dynamic development of the person. In this context, it is important to study the phenomenon of "risk" in the psychological aspect, the mechanisms of risk course, indicators, the ability to take risks. Their absence or insufficiency leads to inadequate assessment of external situations and causes unreasonable risk. The ability to take risks is the ability to combine the initiative and sobriety of the mind, which mean readiness to give preference, to achieve better results than ever. A person who is able to take risks must be psychologically prepared to make effective use of all available resources; to be able to plan his actions.

However, in our opinion, there is a certain ambiguity in the interpretation of "capable of risk", since the term "ability" is used to assimilate the activity and the positive result of its implementation. It is more correct to apply the concept of readiness to risk. A destructive form of risk leads to unreasonable risk, to voluntarism and deviant behavior (risk as a destabilizing factor). 
The factors that determine the uncertainty in the activities of extreme activity representatives are presented ${ }^{8}$ (S. Tomchuk, O. Dobrianskyi, 2013). In our opinion, the extreme activity of border guards is created not by the physical factors of the environment, but by the constantly acting emotional factors. The latter should include not only time deficiency, intellectual overload associated with excess or deficiency of information, but also constant increased service and moral responsibility for taken decision, psycho-emotional tensions, etc. It is worth considering the fact that in the professional activity the border guard faces antisocial, unlawful acts of persons, citizens of border areas, who also affect his psyche. All this causes a constant load on him, professional burnout of the person. Extreme situations that arise in the activities of border guards have their specific psychological content, manifest themselves in certain forms and can be classified in some way by indicators (S. Tomchuk, Dobryanskiy, 2013):

Transience. The activities of the border guard occur in severe time deficiency with maximum mental load of personality, in his readiness for immediate actions at an exceptionally fast pace. This type of situation is characterized by unexpectedness, the novelty of its individual elements, the speed of occurrence, lack and contradiction of information, the intense functioning of thinking, the transience of mental processes. The main factor in this situation is the suddenness, so it is of great importance that the border officer has the appropriate experience and skills.

Duration. The effective activity of the state border guard in a long-term situation requires stable motives of activity, mental endurance, high mobilization, responsibility, independence and other qualities.

The situation with the element of uncertainty. In this situation, the border guard faces the problem of choosing the only right solution from several possible and equally significant ones. The situations with uncertain components are characterized by the absence or contradiction of information. In solving various problems, adequate motivation, emotional sustainability, high professional training and intellectual capacity become crucial in this situation.

${ }^{8}$ Tomchuk, S., Dobrianskyi, O. (2013). Psychological readiness of investigators for professional activities. Vinnytsia: VOIPOPP. 
A situation that requires readiness for emergency actions. The activity of the border guard in this situation requires a high level of vigilance, speed of mental processes switching, emotional sustainability.

A situation that combines unexpectedness and lack of time is characterized by the need to make the right decision immediately, a high degree of personal responsibility for the taken decisions and actions, the immediate manifestation of the results.

The situation with the receipt of false information. It usually occurs when misinformation is received. It is characterized by the dependence of the number of erroneous decisions and actions on the availability of time and the experience of the military man.

The situation of the "dominant state". It is conditioned by the possibility of complete absorption of attention by any type of activity. It is expressed in the fact that in such a "dominant state" the border guard reacts poorly to other influences, signals and commands, which can lead to negative consequences. It is necessary to use very strong stimuli or warning signals that can bring him out of this "absorption" state.

Critical situation provides an alternative choice of possible activity outcomes: victory or complete psychological defeat. In a critical situation, a person's individual characteristics as well as his main sociopsychological qualities and adaptation capabilities are revealed.

The existence of the subject's uncertainty is due to the incompleteness and insufficiency of information about the object, process, phenomenon to be decided; limitations of the individual in the process of gathering and processing information; with the constant variability of information on many objects and the need to use the "trial and error" method sometimes. However, sources of uncertainty are usually contained within the subject himself, they are individual, and the person takes into account the factors that influence or may influence the success of the activity.

An objective approach to understanding the nature and manifestations of risk focuses primarily on the randomness of the results and the associated negative consequences and does not take into account the personality and variability of personal factors in the risk situation. The subjective approach, while focusing on the assessment of the hazard, the choice of specific behavior, rejects the objective sources of the situation of danger and uncertainty. 
Thus, Ye. Iliin ${ }^{9}$ believes that risk, as a psychological phenomenon, includes the situation of risk, risk assessment, the degree of its awareness by risk subjects, risk factors, the situation of choice, risk limits and risk zone (Iliin, 2012, p. 67). It most often identifies four major risk functions: protective, analytical, innovative, regulatory. The protective function of risk is manifested in the fact that the risk is a normal condition for the subject, so it is necessary to form a rational attitude to failure. The analytic function is related to the necessity to choose one of possible solutions. An innovative function is to stimulate the search for unconventional problem solutions. The regulatory function is controversial and has two forms: constructive and destructive.

In the researches on risk psychology, the most commonly used concepts are "risk object", "risk group", "risk factor", "risk zone" and others. However, these concepts are the prerogative of the social aspect rather than the psychological one, since they do not imply the subjective choice of available alternatives but the existence of dangerous, uncertain situations existing in the society, to which the person is involved for various reasons. It is also important to note that in everyday life, there are actions, activities that are recognized by society as dangerous and a person either avoids them in view of human experience or is ready to accept them.

An object of risk can be represented as an object or phenomenon that actually exist and carry a potential danger to the human individual. Ye. P. Ilyin (2012) identifies a risk factor as conditions (circumstances) that are not direct sources of undesirable results occurrence, but increase the probability of their occurrence ${ }^{10}$. Depending on their probability, the author identifies high, moderate, and low risk factors. It is necessary to distinguish between subjective and objective determinants of risk and its factors. The content of the concept of "objective risk factors" can be interpreted as the inability of the person to influence and change external unfavorable circumstances. In other words, objective risk factors are functions of phenomena that do not depend on human consciousness and are associated with unfavorable

\footnotetext{
${ }^{9}$ Ilyin, Ye., (2012). Psychology of risk. SPb.: St. Petersburg.

${ }^{10}$ Ilyin, Ye., (2012). Psychology of risk. SPb.: St. Petersburg.
} 
features of situations and conditions of their realization. Risk subjectivity can be represented as certain misdeeds that are directly dependent on the subject, the person.

"Risk group" means a particular community that is in a dangerous situation, which is determined by one or more factors. In addition to the peculiarities of human activity, risk involves the presence of conditions that negatively affect his life opportunities. In such conditions, the ability or inability of a person to resist risk factors are manifested $^{11}$ (Ilyin, 2012, p. 185).

The risk zone as a term should be used when this concept is identified with the concept of risk. You can talk about the danger zone only realizing it and deciding to act in it, only then the subject risks.

Risk situations arise only when a subject appears in the situation. However, a dangerous situation is not necessarily a risky situation. Risk in its objective form is not associated with the hazard. For different subjects acting under the same conditions, the situation may be different - risky for one person and non-risky for another one. It is important for the individual to understand the degree of risk. As we have revealed, the same situation is evident for border guards with more or less experience of service.

On the one hand, risk is focused on obtaining socially significant results in extraordinary, new ways in conditions of uncertainty and the situation of inevitable choice. On the other hand, risk can lead to adventurism, voluntarism, subjectivism.

It is important to study the characteristics of the readiness of the individual for risk in the professional activity of border guards. In modern researches, the notion of propensity as readiness to risk is more commonly used. Thus, T.B. Khomulenko (2011) and L.M. Absaliamov (2011) define a propensity to risk as a psychological property, which determines the psychological state of realization of habitual forms of behavior, caused by emotional intrinsic motivation - the need for thrills, and manifests itself in the priority emotional choice of the risky form of activity, spontaneously selected behavior in the conditions of uncertainty and potential threat ${ }^{12}$. That is, the readiness for risk is

${ }^{11}$ Ilyin, Ye., (2012). Psychology of risk. SPb.: St. Petersburg.

12 Khomulenko, T., Absaliamova, L. (2011). Motivational, intellectual, and emotional components of risk psychology: an age dimension. Kharkiv: KhNPU. 
represented by the authors as a psychological trait that determines the psychological state of expectation of a significant external stimulus, caused by external meaningful motivation, and determines the deployment of a particular program, which corresponds to the developed ability to take decisions and act in conditions of uncertainty and potential uncertainty successfully.

In our opinion, in the context of an activity approach, risk is an act of a person's interacting with different factors of environmental reality, in the process of which he tries to achieve the goal consciously. At the same time, its peculiarities are manifested as risky decision making and preparedness for them, risky actions and awareness and assessment of their consequences. In the context of studying such an individual's readiness for risk, it is necessary to investigate the motivational, cognitive, emotional-volitional, connotative components of such readiness of border guards.

The analysis of psychological researches allows us to conclude that there are different ideas about risk readiness ${ }^{13,14}$ (Diachenko, 1985; S. Tomchuk, O. Dobrianskyi, 2013). Readiness to risk is a kind of readiness for extreme actions, which in various studies is presented as a component of courage, as a propensity for risk, as the ability, as a manifestation of certain emotional and volitional qualities, etc. Risk readiness is the ability to take adequate decisions in the conditions of uncertainty and the readiness to control potential changes consciously through the implementation of one's own decisions, the ability to set goals that allow to test the one's capabilities, expand them, and go beyond situational constraints. For Yu. Kozeletskyi (1979), readiness to take risks embraces the qualities of courage ${ }^{15}$.

It is for the individuals who act in extreme conditions the propensity and readiness to risk are professionally important personal indicators. In the researches they use the definition of "risk ability", which refers to the potential and practical realization of the subject's ability to act successfully in dangerous situations with

${ }^{13}$ Tomchuk, S., Dobrianskyi, O. (2013). Psychological readiness of investigators for professional activities. Vinnytsia: VOIPOPP.

${ }^{14}$ Diachenko, M., (1985). Willingness in Tense Situations. Minsk: University Publishing House.

${ }^{15}$ Kozeletskyi, Yu., (1979). Psychological theory of solutions. M.: Progress. 
uncertain results, and is defined by a set (individual, professional, etc.) of the qualities necessary for its implementation. The ability to take risks is analyzed as a position of inner fighting spirit, the desire to make every effort, the ability to take another step that a person did not take if guided by a sense of comfort, the ability to act always, at any point of his life. The notion of "risk taking" has a positive effect on professional development, and excessive caution, on the contrary, limits the ability of a person's professional selfrealization.

In the context of occupational risk-related activities, the role of typological features and properties of the nervous system is also emphasized. Ye. P. Ilyin believes that the major factor in these professions is experiencing the danger because of having a great deal of personal responsibility. Stressful situations lead to impaired sensory and mental activity ${ }^{16}$. The person does not perceive the situation adequately and accordingly taking wrong decisions, and sometimes even forgetting what is needed (Ilyin, 2012).

A person's ability to act in a risky, extreme situation arises directly from the properties of his temperament, in particular from the properties of the nervous system strength. Psychologists associate the propensity to risk with extraversion and impulsiveness in activity.

Emergency readiness is analyzed as the ability to respond adequately and quickly to emergencies with uncertain timing and high probability of their occurrence. The person's ability to act effectively in a risky situation is associated with such person's traits as emotional stability, ability to plan and predict, self-control, ability to change attitudes, lack of conservatism, positive attitude and internal locus of control. The ability to respond effectively to risk is influenced by the level of personal anxiety and self-esteem ${ }^{17}$ (Kotik, 1989). Significant for the effectiveness of activity in risky conditions is the ability to selfregulate mental activity.

${ }^{16}$ Ilyin, Ye., (2012). Psychology of risk. SPb.: St. Petersburg.

${ }^{17}$ Kotik, M., (1989). Psychology and security. Tallin: Walgus. 


\section{Experimental study of border guards' psychological readiness for risk}

In order to study the peculiarities of psychological readiness of the officers of the State Border Guard Service of Ukraine to risky behavior in professional activities, we conducted a statutory research on a sample of early adulthood respondents (aged 22 to 30) The total sample consisted of 301 officers, of whom 101 were with a length of service at the border up to 3 years, 200 officers with a length of service of 4 to 8 years. In the research, in order to study the features of occurrence of border guards' indicators that characterize their psychological readiness for risk in professional activities, we used a complex of known in psychology methods and techniques: observation, oral and written questioning, testing, methods of mathematical processing of research results (factor, correlation and cluster analysis, Fisher's criterion for determining the significance of differences in indicators, etc.). The following methods were used as test ones: M. Zuckerman's test for self-esteem predisposition to risky behavior, "Questionnaire of qualitative indicators of risk inclination in different spheres of life" (O.P. Sannikov, S.V. Bykov), methods to diagnose: person's tolerance for uncertainty (D. McLain), motivation for success and avoidance of failures (A.A. Mehrebian), "Model of behavior in stressful situations" (S. Hobfall scale), "Diagnosis of strategies of behavior in conflict" (K. Thomas), Coping strategies (R. Lazarus) and others.

To determine the typology of person' risk and to determine its components for border guards, the methods were used from the research of O. Vdovichenko (2019). ${ }^{18}$ The procedure of cluster analysis by the K-means method for factor loadings was carried out and the types of military men were determined by risk factors: "impulsive risky" officers (about 50\% of young officers, $48 \%$ - in the group of the age 25-30), "low risky" officers (respectively $22.5 \%$ and $25.5 \%)$, "high risky" officers (27.5\% and $26.5 \%$ respectively).

${ }^{18}$ Vdovichenko, O., (2019). Psychological bases of person's risk in ontogeny. (diss. doc. psych.). PSU named after K. D. Ushynskyi, Odesa. 
As we find out, the officers of the impulsive-risky type are the most common in both groups. Some more of these officers are the ones with up to three years of service experience. The inclination risk among impulsive risky officers is manifested in the display of inadequately high demands on themselves, their lives, and their close people, ways and means of solving life's difficulties, as well as in the need to make their professional life brighter. The researched ones of this type are characterized by low risk readiness, impulsiveness in actions, decision making and emotionality. It is this behavior that is more specific to young officers than to those who have much more experience at the border.

The border guard officers who are a part of the low risky group are characterized by moderate, prudent behavior, rationality and no apparent risk inclinations.

The high risky officers are eager for new experiences, thrills and emotions. They are burdensome with such one-of-a-kind, dayto-day work the border guard service is, sometimes creating unnecessary difficulties on their own, problems that generally complicate their lives and the lives of others, deciding whether or not to perform a risky act is an important component of a person's risk functioning. That is why our study examined the correlation between certain indicators, the components of person's risk for the entire sample of border guard-officers aged 22-30. The results are presented in table. 1 .

Table 1

\section{Correlation between decision taking indicators}

and risk factors of the border guards

\begin{tabular}{|l|c|c|c|}
\hline \multirow{2}{*}{$\begin{array}{c}\text { Scales } \\
\text { of decision } \\
\text { taking }\end{array}$} & $\begin{array}{c}\text { Integral } \\
\text { component } \\
\text { of person's risk }\end{array}$ & $\begin{array}{c}\text { The cognitive } \\
\text { component } \\
\text { of person's risk }\end{array}$ & Impulsiveness \\
\hline Vigilance & $-0,64 * * *$ & - & $-0,17 * *$ \\
\hline Avoidance & $0,43 * * *$ & - & $0,32 * * *$ \\
\hline Procrastination & $0,39 * * *$ & $-0,16^{* *}$ & - \\
\hline Custody & $0,51 * * *$ & - & $0,28 * * *$ \\
\hline
\end{tabular}

Notes: ${ }^{*}-\mathrm{p}<0.05 ; * *-\mathrm{p}<0.01 ; * * *-\mathrm{p}<0.001$. 
The "integral component of person's risk" is characterized by the desire for risk in interpersonal communication, in the sphere of health, service and everyday life, non-adaptive desire for difficulties, intolerance to monotony, search for new experiences and thrills. It is characterized by a lack of vigilance in decision-making, impulsiveness in choosing behavioral strategies, in particular in situations of risk, avoidance of responsibility for decisions, high emotional arousal and uncertainty in the situation of choice of alternative decisions. The high level of development of this risk component of officers implies excessive speed and impulsiveness in considering and choosing alternative ways of solving the problem, disclaiming responsibility for the taken decision, shifting responsibility to others, postponing such a choice.

The "cognitive component of person's risk" is negatively associated with procrastination in decision making. Therefore, high risk tolerance and risk readiness are inherent for border guards who are not inclined to delay decision-making until later. "Impulsivity" as a component of person's risk, characterized by excessive emotionality in risk situations, is negatively associated with vigilance in decisionmaking and positively - with vigilance and avoidance of decisionmaking. Consequently, high emotionality in risk situations, impulsiveness as a factor in the exercise of risky behavior inherent to the researched ones who take decisions very quickly, neglecting to consider all possible alternatives, with turbulent emotional experiences, which can have negative consequences actually.

The study revealed that officers have a high level of risk and extreme behavior inclination against the background of low subjective assessment of situations as dangerous, characterized by high emotionality in the evaluation of experience, a tendency to soulsearching in the assessment of the situation and their actions in it, orientation to their emotions and feelings, not an objective assessment of the consequences of their behavior. The peculiarities of reflecting one's own behavior in the border guards' risk situations depend on the person's risk typology. As person's risk indicators grow, the ability to reflect on the causes and effects of the risk situation systematically and its own role in it decreases, impulsive persons are more likely to be introduced to introspection, and lowrisk people - to systemic reflection. 
During the empirical study, the role of cognitive factors in determining a border guard-officer's personality risk was examined. The table 2 presents the relationship between person's risk factors and such cognitive indicators as creativity.

Table 2

\section{Indicators of creativity of border guards} with different types of risk

\begin{tabular}{|c|c|c|c|c|}
\hline \multirow{2}{*}{$\begin{array}{c}\text { Scales } \\
\text { of creativity }\end{array}$} & \multicolumn{3}{|c|}{ Types of person's risk $(M \pm 0)$} & \multirow{2}{*}{$\begin{array}{c}\text { Probability } \\
\text { of results }\end{array}$} \\
\hline & $\begin{array}{c}\text { Impulsively } \\
\text { risky }\end{array}$ & $\begin{array}{l}\text { Low } \\
\text { risky }\end{array}$ & High risky & \\
\hline Speed & $5,67 \pm 1,81$ & $4,75 \pm 1,91$ & $6,17 \pm 1,59$ & $\mathrm{p}<0,01$ \\
\hline Originality & $11,00 \pm 4,14$ & $7,64 \pm 1,44$ & $11,60 \pm 4,89$ & $\mathrm{p}<0,001$ \\
\hline $\begin{array}{l}\text { The degree } \\
\text { of development } \\
\text { of the creative } \\
\text { product }\end{array}$ & $4,89 \pm 1,88$ & $5,53 \pm 2,16$ & $6,20 \pm 1,53$ & $\mathrm{p}<0,01$ \\
\hline
\end{tabular}

It was found out that "Integral component of person's risk" and "Cognitive component of person's risk" correlate with indicators of speed and originality positively. Impulsivity correlates negatively with the degree of creative product development, so the higher the emotionality and impulsiveness are in the risk structure of an officer's personality, the lower the indicators are in officer's performing creative tasks. High level of propensity and readiness to take risks characterizes the officer as the most creative, capable of solving creative tasks personality.

The influence peculiarities of motivational and regulatory factors on the border guards' risk were studied, in particular such indicators as viability, volitional self-control and motivation for success. Motivational and regulatory factors of those subjects belonging to different types of person's risk were compared.

The research revealed that the border guards have a negative relationship between the factor of "Integral component of person's risk" and involvement and control as well as between the factor of "Impulsivity" and the control indicator. A positive correlation was found between the factor "Cognitive component of person's risk" and 
the risk acceptance. In general, the risk of an officer's personality is characterized by low viability indicators. The border guards under study differ in their viability scales depending on the types of person's risk.

The "impulsive-risky" type of officers has the lowest engagement rates compared to other types. They choose risky behavior to achieve the goal, but they are less convinced that being involved in the event gives them the maximum chance of finding something worthwhile and interesting.

The indicators of control in the structure of viability are the highest in the low-risky group. Therefore, the greater the conviction is that life can be controlled, the less the border guards' propensity is to take risks. Risk-taking is more inherent for high-risky individuals. An officer who views life as a way of gaining experience is prepared to act in the absence of reliable guarantees of success, at his own risk, believing that the pursuit of simple comfort and safety impoverishes his life and he is more likely to show a high propensity and readiness to take risks.

The high indicators of border guards' propensity and readiness to risk are manifested in the orientation not of action but of state. With low volitional self-regulation, the low levels of attention randomness are characteristic, as well as excessive emotionality is that accompanies the process of activity and is not aimed at achieving results. High person's risk, and especially excessive impulsiveness and emotionality in situations of risk, are peculiar to persons who are characterized by emotional tension.

Impulsive type researched subjects are characterized by low risk readiness and decision-making, emotionality, and difficulties in initiating action. Low-risk persons are characterized by moderate levels of readiness and inclination for risk, they are characterized by a greater focus on action, eliminate all obstacles to the realization of intent effectively, have a higher level of volitional self-regulation.

One of the indicators of motivation for person's risk is the motivation to succeed or a fear of failure. Features of its manifestation in the group of border guards are presented in Table 3. 
Table 3

Motivation for success/fear of failure of border guards in situations of risk

\begin{tabular}{|c|c|c|c|}
\hline $\begin{array}{c}\text { Types of } \\
\text { person's } \\
\text { risk } \\
\end{array}$ & $\begin{array}{l}\text { Category of border } \\
\text { guard-officers }\end{array}$ & $\begin{array}{c}\begin{array}{c}\text { Motivation } \\
\text { for } \\
\text { success/failure }\end{array} \\
\end{array}$ & $\begin{array}{c}\text { Probability } \\
\text { of } \\
\text { results }\end{array}$ \\
\hline \multirow{2}{*}{$\begin{array}{l}\text { Impulsively } \\
\text { risky }\end{array}$} & $\begin{array}{l}\text { With service experience } \\
\text { of up to } 3 \text { years }\end{array}$ & $164,89 \pm 19,06$ & $\mathrm{p}<0,001$ \\
\hline & $\begin{array}{l}\text { With service experience } \\
\text { of } 4-8 \text { years }\end{array}$ & $154,89 \pm 18,07$ & $\mathrm{p}<0,001$ \\
\hline \multirow{2}{*}{ Low risky } & $\begin{array}{l}\text { With service experience } \\
\text { of up to } 3 \text { years }\end{array}$ & $130,57 \pm 18,74$ & $\mathrm{p}<0,001$ \\
\hline & $\begin{array}{l}\text { With service experience } \\
\text { of } 4-8 \text { years }\end{array}$ & $138,57 \pm 17,52$ & $\mathrm{p}<0,001$ \\
\hline \multirow{2}{*}{ High risky } & $\begin{array}{l}\text { With service experience } \\
\text { of up to } 3 \text { years }\end{array}$ & $184,57 \pm 15,18$ & $\mathrm{p}<0,001$ \\
\hline & $\begin{array}{l}\text { With service experience } \\
\text { of } 4-8 \text { years }\end{array}$ & $191,35 \pm 14,06$ & $\mathrm{p}<0,001$ \\
\hline
\end{tabular}

We come to the conclusion that the higher an officer's motivation to succeed is, the greater his risk inclination in various areas of professional activity and extreme behavior is. High risky border guards are more focused on achievement and low risky ones are focused on fear of failure. The high inclination and psychological readiness of officers, under the condition of less subjective assessment of risk situations, imply a greater orientation towards overcoming difficulties and high achievements in their professional activities. "Low risky" officers are characterized by greater rationality, less uncertainty and higher subjective risk assessment, they foresee the fear of failure naturally, i.e. avoid situations where the loss of something valuable or failure are possible.

High risky persons have the highest rates of desire for excellence. Generally, this type of person's risk is a leader in the pursuit of excellence, but the type of motivation - the focus on achievement or the fear of failure - reinforces this influence. The "Impulsive-risky" type is characterized by a fear of failure and the lowest desire. High risky persons have been found to have the highest rates of striving for superiority and excellence. The type "Impulsive-risky" is characterized by a fear of failure and the lowest desire for excellence. 
Among the connotative factors of personality risk, one can consider the features of coping strategies and other behavioral ways of dealing with conflict, stress and difficult life situations.

It is established that the factor "Integral component of person's risk" of the officers is correlated positively with the indicators of strategies of discharge, removal, fatalism, fantasies, denial, self-blame and comparison. Negative links are made with strategies for rational action, seeking help, persistence, positive thinking, distraction, stepby-step actions, controlling emotions, caution, gaining strength, leaving, self-change, restraint, humor, indecision. Thus, the high risk of person at the stage of becoming a border guard-officer is characterized by a tendency to manifest extreme and risky behavior in various spheres of life, associated with destructive strategies for conflict resolution, manifested in emotional response, autoaggression, and inability to resolve the conflict rationally.

The factor "Cognitive component of person's risk" is associated with indicators of strategies of persistence and distraction positively, but with the indicators of strategies of rational actions, seeking help, expression of feelings, positive thinking, calm and gaining strength, restraint, indecision, feelings of guilt negatively. Therefore, the border guards' high readiness for risk and awareness of the need and importance of risk imply a persistent resolution of the conflict situation, the ability to divert from the source of the conflict, an inability to resolve the conflict rationally. The "Impulsiveness" factor correlates with indicators of strategies of elimination, expression of feelings, fantasies, caution, overcoming and belief positively, but with the strategy of distraction, comfort, humor negatively. The impulsive side of a person's risk, which is manifested in the experience of positive emotions in situations of risk, emotional attraction to dangerous situations, associated with the removal from the problem in a conflict situation, the desire to express their feelings in conflict, to overcome it. High impulsivity of person's risk within a certain type is logically correlated with an inability to control and restrain one's emotions in a conflict situation.

The low risky persons are dominated by strategies for rational action, seeking help, gaining strength and humor. At the very least level, this type uses strategies of discharge, alienation, fatalism, fantasy, denial, self-blame, comparison and reassurance. The high 
risky type use fantasy, disengagement strategies and avoid strategies of restraint, self-change, gaining strength, caution, controlling emotions, comforting and staged actions.

\section{CONCLUSIONS}

A theoretical and experimental study of the features of the psychological readiness of border guard-officers in the professional activities suggests that the level of their formation among young officers is much better. Thus, it is necessary to form such readiness in the educational process of the NASBGS of Ukraine. In future, it is planned to develop and experimentally test a special program of formation of the indicated readiness among the cadets of the Academy.

\section{SUMMARY}

The material presents the results of theoretical analysis of research on the problem of the psychological readiness of border guards to risk in their professional activities. Different approaches to the problem are analyzed, the factors, components, indicators of determined readiness are distinguished. An experimental research of the forming officers' psychological readiness for risk, depending on their types and length of service experience is conducted.

The analysis of person's propensity to risk by motivational, cognitive, connective components in impulsively risky, low and high risky types of border guards is analyzed. Possible outcomes of their behavior and service at the border are described. Directions for further studies of the problem are suggested.

\section{REFERENCES}

1. Kozeletskyi, Yu., (1979). Psychological theory of solutions. Moscow: Progress.

2. Ilyin, Ye., (2012). Psychology of risk. SPb.: St. Petersburg.

3. Petrovskyi, V., (1974). Human behavior in situations of danger (to the psychology of risk). New researches in psychology, (1), p. 23-24.

4. Petrovsky, A., Yaroshevskyi, M. (Eds.). (1990). Short Psychological Dictionary. M.: Politizdat.

5. Aisenk, H., Aisenk, M. (2001). Research of the human psyche. M.: EKSMO-Press. 
6. Tomchuk, S., Dobrianskyi, O. (2013). Psychological readiness of investigators for professional activities. Vinnytsia: VOIPOPP.

7. Khomulenko, T., Absaliamova, L. (2011). Motivational, intellectual, and emotional components of risk psychology: an age dimension. Kharkiv: KhNPU.

8. Diachenko, M., (1985). Willingness in Tense Situations. Minsk: University Publishing House.

9. Kotik, M., (1989). Psychology and security. Tallin: Walgus.

10. Vdovichenko, O., (2019). Psychological bases of person's risk in ontogeny. (diss. doc. psych.). PSU named after K.D. Ushynskyi, Odesa.

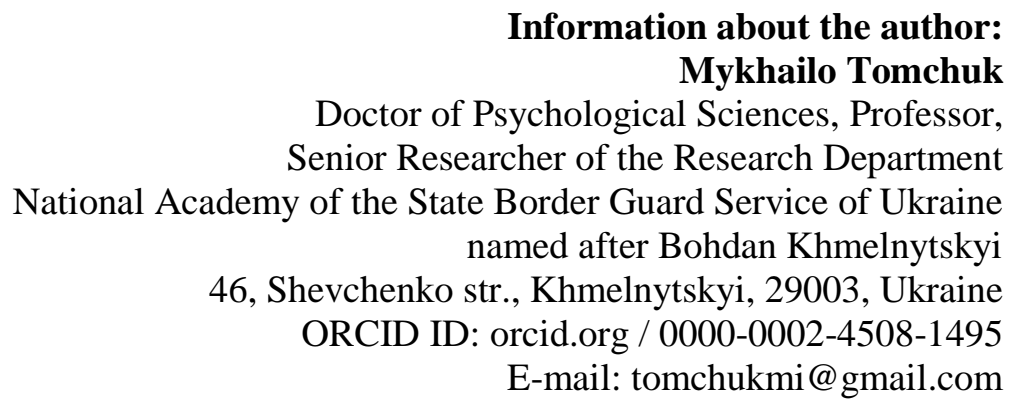

